\title{
Selective solvent extraction for the simulation of oil expulsion and evaluation of shale oil potential
}

\author{
W.L. JIA ${ }^{1 *}$, Q. WANG ${ }^{1}$, W.Z. ZHANG ${ }^{2}$, P.P. PENG ${ }^{1}$
}

${ }^{1}$ Guangzhou Institute of Geochemistry, Chinese Academy of Scicencs, Guangzhou, China

${ }^{2}$ Changqing oilfield company, PetroChina, Xi'an, China

Oil expulsion is crucial to determining the amount of residual oil as well as to late gas potential for shale play. Organic fractionation between expelled and residual oils is one of the key characters of oil expulsion and accordingly worthy of being considered in evaluating the shale oil and gas potentials. Extraction using solvents with relatively low polarity was tested here for its usefulness of indicating the chemical fractionation through simulation experiment and geological samples.

For lacustrine shale samples, group compositions of the extracts obtained using petroleum ether are distinct from those after dichloromethane extraction. The former are overall similar to those of tight oil having very low amount of polars, although relative amount of aromatic fraction is slightly larger. Extraction yields using petroleum ether could be larger or smaller than S1 values, and both of them are smaller than extraction yields with dichloromethane. This could be related to different TOC contents and maturities for shales. Extraction using low polarity has the advantage to determining the group composition. However, biomarker and carbon isotopic characteristics show few differences between the two kinds of extracts, suggesting that source indicators are not greatly affected.

For thermal simulation experiments, selective solvent extraction yielded significant differences in group compositions between expelled oil and kerogen-sorbed oil. Generally, larger amount of hydrocarbons existed in expelled oil than in retained oil, and more polars could be expelled for type I kerogen than types II/III kerogen. In addition, the mass ratios of expelled to retained oil greatly decrease from type I, through type II and to type III kerogens, suggesting larger oil expulsion efficiency for shale having greater oil-generation potential. These are consistent with the variations previously reported by many studies.

Selective solvent extraction could a useful tool for simulating organic fractionation during the oil expulsion and thus determining shale oil and gas potential. Practically, the solvent type or composition efficiency may vary with kerogen type in specific shale play. 